\begin{tabular}{|c|l|}
\hline Title & $\begin{array}{l}\text { Deuterium retention and desorption behavior of reduced activated ferritic steel with surface damage due to high energy } \\
\text { helium ion irradiation }\end{array}$ \\
\hline Author(s) & Y amauchi, Y.; Gotoh, K.; Nobuta, Y.; Hino, T.; Suzuki, S.; A kiba, M. \\
\hline Citation & $\begin{array}{l}\text { Fusion Engineering and Design, 85(10-12), 1838-1840 } \\
\text { https://doi.org/10.1016/.fusengdes.2010.06.007 }\end{array}$ \\
\hline Issue Date & 2010-12 \\
\hline Doc URL & http://hdl.handle.net/2115/47258 \\
\hline Type & article (author version) \\
\hline File Information & FED85-10-12_1838 1840.pdf \\
\hline
\end{tabular}

Instructions for use 
Deuterium retention and desorption behavior of reduced activated ferritic steel with surface damage due to high energy helium ion irradiation

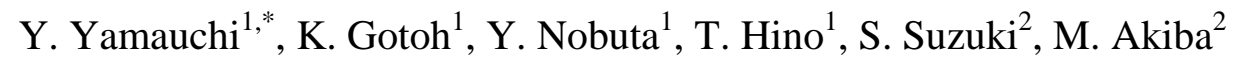

${ }^{1}$ Laboratory of Plasma Physics and Engineering, Hokkaido University, Sapporo, Japan

${ }^{2}$ Fusion Research and Development Directorate, Japan Atomic Energy Agency, Naka, Japan

[*Corresponding Author]

Name: $\quad$ Yuji Yamauchi

Postal address: Laboratory of Plasma Physics and Engineering, Hokkaido

University, Kita-13, Nishi-8, Kita-ku, Sapporo, Hokkaido, 060-8628 Japan

Phone\&Fax Number: $\quad$ +81-11-706-7108

E-mail address: $\quad$ yamauchi@qe.eng.hokudai.ac.jp 


\title{
Deuterium retention and desorption behavior of reduced activated ferritic steel with surface damage due to high energy helium ion irradiation
}

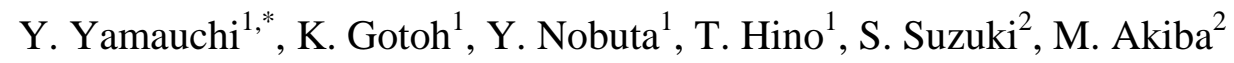

${ }^{1}$ Laboratory of Plasma Physics and Engineering, Hokkaido University, Sapporo, Japan, yamauchi@qe.eng.hokudai.ac.jp

${ }^{2}$ Fusion Research and Development Directorate, Japan Atomic Energy Agency, Naka, Japan

\begin{abstract}
Reduced activation ferritic-martensitic steel F82H was irradiated with $5 \mathrm{keV}$ helium ions to introduce the surface damage. After the irradiation, the irradiated F82H was continuously exposed to $1.7 \mathrm{keV}$ deuterium ions. The effects of the damages introduced by the helium ion irradiation on deuterium retention and desorption behavior of F82H were investigated. The HD desorption had a peak at around $500 \mathrm{~K}$, which was shifted to the high temperature region when the helium ion fluence increased. The decrease in HDO desorption at the high fluence region was observed. This might be owing to the oxygen depletion on the surface by the sputtering. The amount of retained deuterium of the F82H gradually increased with the helium ion fluence and saturated at 7.2 dpa.
\end{abstract}

KEYWORDS: deuterium retention, surface damage, F82H, thermal desorption 


\section{Introduction}

Reduced activation ferritic-martensitic steel F82H is one of candidate materials for the first wall in fusion reactor [1, 2], and many studies on this steel has been reported so far [3]. The first wall in the reactor receives various particles, such as neutron and helium ash, and then the damages are introduced into the surface. These damages might affect the hydrogen isotope retention and desorption behavior, which is associated with the safety issue and fuel density control. Authors have reported that the effect of helium ion pre-irradiation on hydrogen retention and desorption properties for polycrystalline tungsten [4]. In the pre-irradiated case, the desorption in the low temperature region was significantly enhanced. However, the effects of the radiation damages on deuterium retention and desorption properties for the $\mathrm{F} 82 \mathrm{H}$ steel have not been sufficiently investigated so far.

In the present study, the F82H steel was irradiated with high energy helium ions to introduce the surface damage. After the irradiation, the deuterium retention and desorption behavior of the pre-irradiated F82H was evaluated.

\section{Experiment}

The F82H sample with a size of $22 \mathrm{~mm} \times 5 \mathrm{~mm} \times 0.1 \mathrm{mmt}$ was mechanically polished by $\mathrm{Al}_{2} \mathrm{O}_{3}$ powders and then cleaned using an ultrasonic bath with ethanol. After the cleaning, the F82H sample was exposed to helium ion with energy of $5 \mathrm{keV}$ at room temperature using an ECR ion source [4]. The helium ion fluence changed in the range of $(0.5-10) \times 10^{17} \mathrm{He} / \mathrm{cm}^{2}$. These fluences corresponded to the surface damage in the range of 1.8-36 dpa, which were estimated by SRIM-code 2006. After the helium ion irradiation, the F82H was irradiated to deuterium ion with energy of $1.7 \mathrm{keV}$ at the 
same apparatus. The deuterium ion fluence was $1.0 \times 10^{18} \mathrm{D} / \mathrm{cm}^{2}$. The irradiation temperature was room temperature. After that, the deuterium retention and desorption behavior of the irradiated $\mathrm{F} 82 \mathrm{H}$ was examined by using a technique of thermal desorption spectroscopy, TDS. The irradiated sample was introduced into TDS device [5] and then linearly heated from room temperature to $1073 \mathrm{~K}$ with a ramp rate of 0.5 $\mathrm{K} / \mathrm{s}$. During the heating, the gas desorption from the sample was quantitatively measured by a quadrupole mass spectrometer. By integrating the desorption rate with respect to the heating time, total amount of desorbed gases, namely, total amount of retained gases could be obtained.

\section{Results}

The deuterium retained in the sample after the deuterium ion irradiation was desorbed in forms of $\mathrm{HDO}, \mathrm{HD}, \mathrm{D}_{2}$ and $\mathrm{D}_{2} \mathrm{O}$ during the TDS measurement. Figure 1 shows thermal desorption spectra of HD for F82H samples with or without the helium pre-irradiation. The HD desorption for the F82H without the pre-irradiation had a sharp peak around $500 \mathrm{~K}$. The HD desorption was clearly enhanced by the helium preirradiation. Also, the peak temperature was shifted to the high temperature region for the case with the pre-irradiation. Figure 2 shows thermal desorption spectra of HDO for F82H samples with or without the helium pre-irradiation. The HDO desorption rate started to increase around $350 \mathrm{~K}$ and then had a maximum around $500 \mathrm{~K}$. The peak temperature of the HDO desorption did not change by the helium pre-irradiation, on the contrary to the case of the HD desorption. Figure 3 shows time evolution of $\mathrm{m} / \mathrm{e}=4$ signal intensity during the TDS measurement for F82H samples with or without the helium pre-irradiation. These signals were associated with the desorptions of $\mathrm{D}_{2}$ and He 
from the irradiated samples. In the case without the pre-irradiation, the $\mathrm{m} / \mathrm{e}=4$ signal had only a peak around $500 \mathrm{~K}$, which was similar to that for HD desorption. In the case with the helium pre-irradiation, additional peaks appeared in the temperature region above $700 \mathrm{~K}$. In addition, the peak temperature around $500 \mathrm{~K}$ was shifted to the high temperature region. This peak shift was also observed for the HD desorption. Sugano et al have reported on thermal helium desorption from reduced activation martensitic steel, JLM-1, irradiated by energetic helium ions [6]. In the case of the high fluence, the helium desorptions around and above $800 \mathrm{~K}$ became significantly large. This evidence and the comparison between the evolution of $\mathrm{m} / \mathrm{e}=4$ signal and HD desorption feature suggest that the implanted helium was desorbed at high temperature region, around $800 \mathrm{~K}$. The amounts of desorbed $\mathrm{D}_{2}$ from the irradiated samples were estimated under the assumption that the $\mathrm{D}_{2}$ desorption occurred around $500 \mathrm{~K}$.

Figure 4 shows the amount of desorbed gases containing deuterium atom from the deuterium-irradiated $\mathrm{F} 82 \mathrm{H}$ as a function of the surface damage introduced by helium ion fluence prior to the deuterium ion irradiation. The amounts of $\mathrm{HD}$ and $\mathrm{D}_{2}$ gradually increased with the surface damage and then saturated. The HDO desorption also increased by the helium pre-irradiation at low fluence region, while the decrease with increase of the damage at the high fluence region was observed. This decrease might be owing to the oxygen depletion at the surface by the sputtering.

Figure 5 shows the amount of retained deuterium as a function of surface damage introduced by helium ion irradiation prior to the deuterium ion irradiation. The amount of retained deuterium of the F82H gradually increased with the damage and saturated at $7.2 \mathrm{dpa}$, which corresponded to the fluence of $\sim 2 \times 10^{17} \mathrm{He} / \mathrm{cm}^{2}$. The increase in 
deuterium retention might be accompanied with the increase in trapping site for implanted deuterium by the helium pre-irradiation.

\section{Conclusion}

Effects of energetic helium pre-irradiation on the deuterium retention and desorption properties for reduced activation ferritic-martensitic steel, F82H, were investigated. The HD desorption had a peak at around $500 \mathrm{~K}$, which was shifted to the high temperature region when the helium ion fluence increased. The decrease in HDO desorption at the high fluence region was observed. The amount of retained deuterium of the F82H gradually increased with the helium ion fluence and saturated at $7.2 \mathrm{dpa}$. The obtained results indicate that the surface damage and the surface modification introduced by the helium irradiation strongly affected the deuterium retention of the F82H.

\section{Acknowledgement}

This work was supported by a Grand-in-Aid for Young Scientists (B), MEXT KAKENHI 20760575.

\section{References}

[1] K. Shiba, A. Hishinuma, A. Kohyama, K. Kasamura, Properties of low activation ferritic steel F82H IEA Heat, JAERI-Tech 97-038, JAERI, 1997.

[2] H. Tanigawa, T. Hirose, K. Shiba, R. Kasada, E. Wakai, H. Serizawa, Y. Kawahito, S. Jitsukawa, A. Kimura, Y. Kohno, A. Kohyama, S. Katayama, H. Mori, K. Nishimoto, R.L. Klueh, M.A. Sokolov, R.E. Stoller, S.J. Zinkle, Technical issues of 
reduced activation ferritic/martensitic steels for fabrication of ITER test blanket modules, Fusion Eng. and Design 83 (2008), 1471-1476.

[3] For example, E. Wakai, M. Ando, T. Sawai, H. Tanigawa, T. Taguchi, R.E. Stoller, T. Yamamoto, Y. Kato, F. Takada, Effect of heat treatments on tensile properties of F82H steel irradiated by neutrons, J. Nucl. Mater. 367-370 (2007), 74-80.

[4] T. Hino, K. Koyama, Y. Yamauchi, Y. Hirohata, Hydrogen retention properties of polycrystalline tungsten and helium irradiated tungsten, Fusion Eng. and Design 3940 (1998), 227-233.

[5] Y. Yamauchi, Y. Hirohata, T. Hino, K. Masaki, M. Saidoh, T. Ando, D. G. Whyte, C. Wong, Deuterium retention of DIII-D DiMES sample, J. Nucl. Mater. 266-269 (1999), 1257-1260.

[6] R. Sugano, K. Morishita, H. Iwakiri, N. Yoshida, Effects of dislocation on thermal helium desorption from iron and ferritic steel, J. Nucl. Mater., 307-311 (2002), 941945. 
Figure Captions

Figure 1 Thermal desorption spectra of HD for F82H samples with or without the helium pre-irradiation.

Figure 2 Thermal desorption spectra of HDO for F82H samples with or without the helium pre-irradiation.

Figure 3 Time evolution of $\mathrm{m} / \mathrm{e}=4$ signal intensity during the TDS measurement for F82H samples with or without the helium pre-irradiation.

Figure 4 Amount of desorbed gases containing deuterium atoms from the deuteriumirradiated $\mathrm{F} 82 \mathrm{H}$ as a function of the surface damage introduced by helium ion irradiation prior to the deuterium ion irradiation.

Figure 5 Amount of retained deuterium as a function of surface damage introduced by helium ion irradiation prior to the deuterium ion irradiation. 


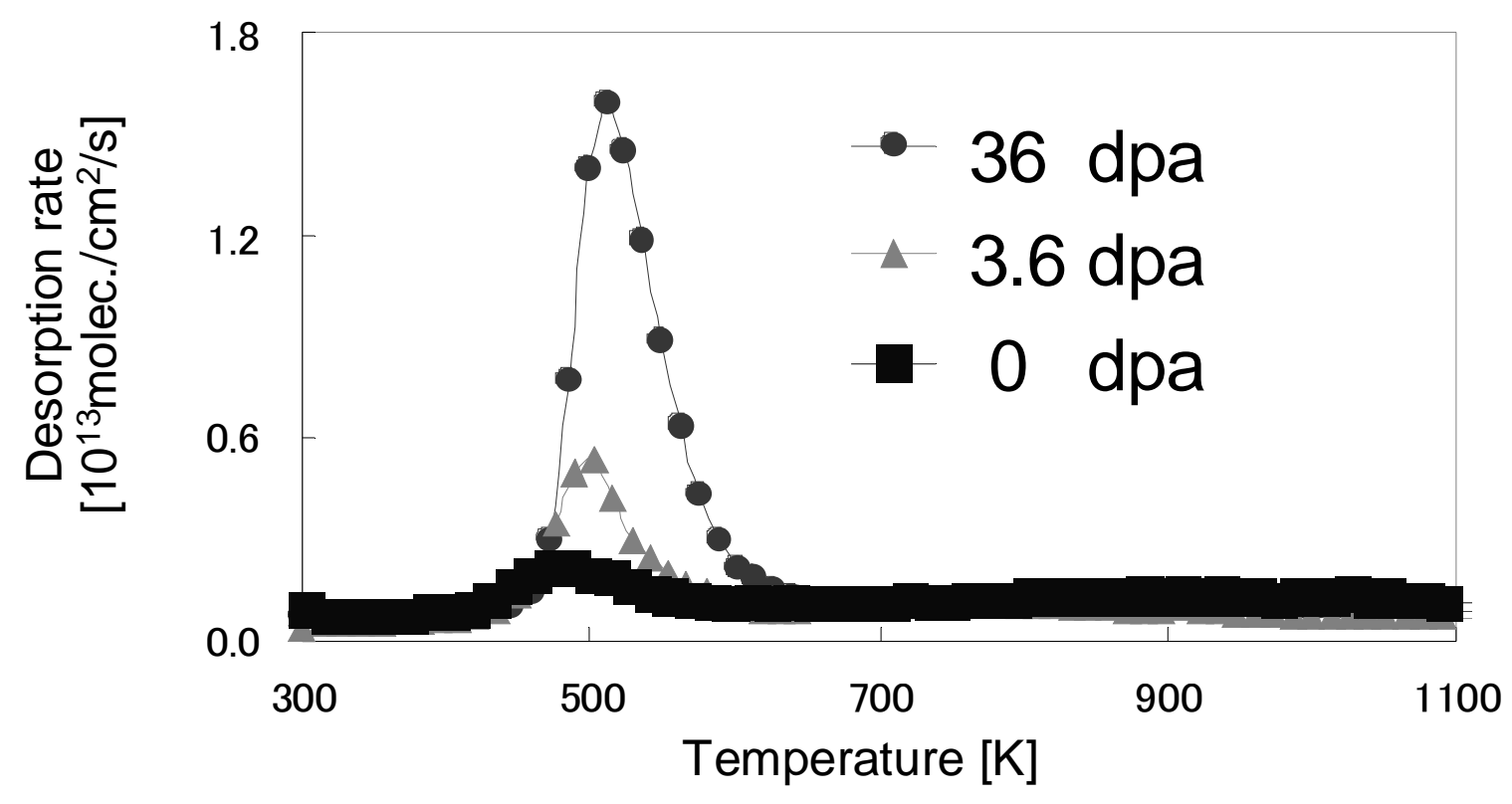

Figure 1 Thermal desorption spectra of HD for F82H samples with or without the helium pre-irradiation. 


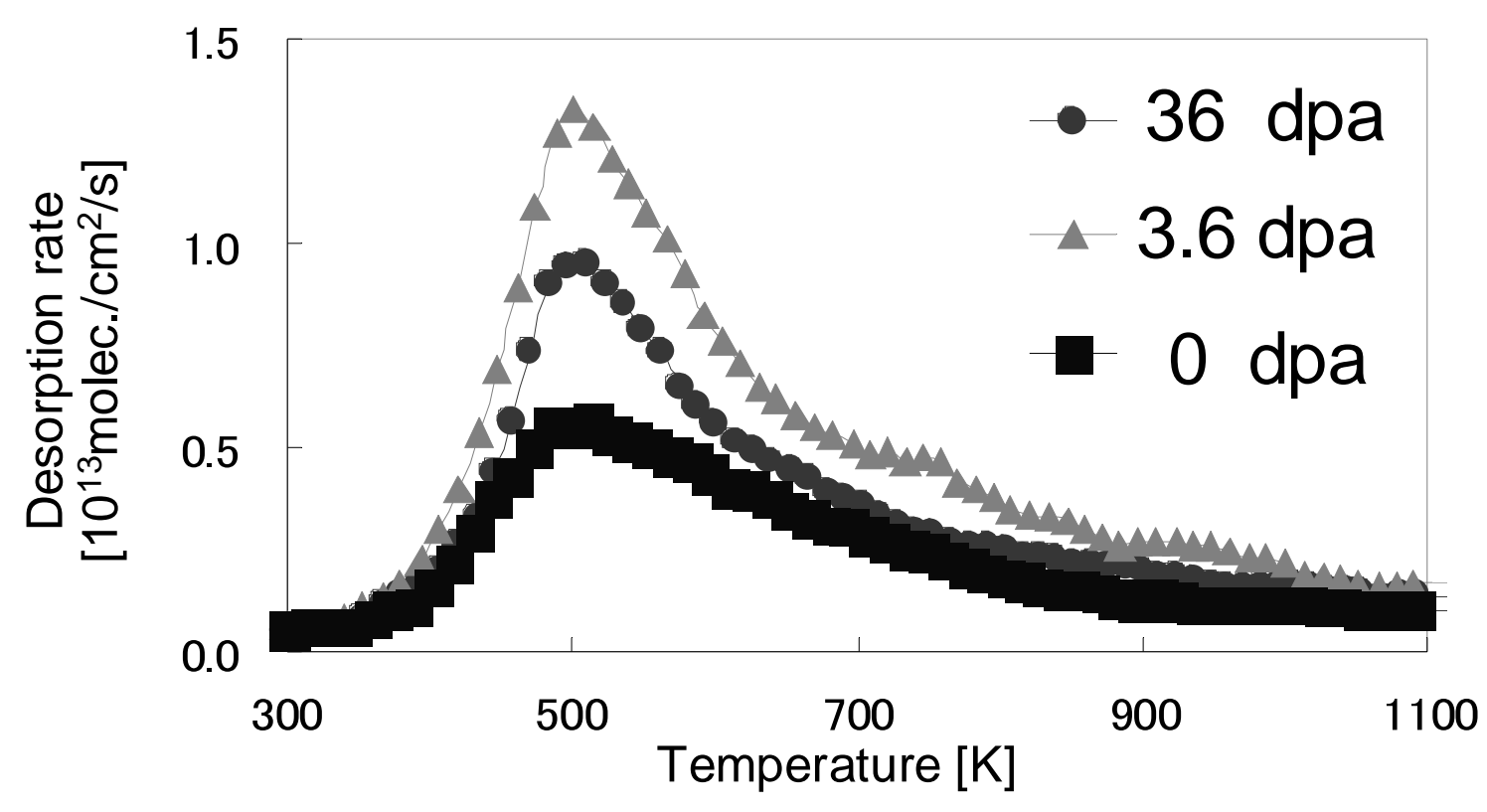

Figure 2 Thermal desorption spectra of HDO for F82H samples with or without the helium pre-irradiation. 


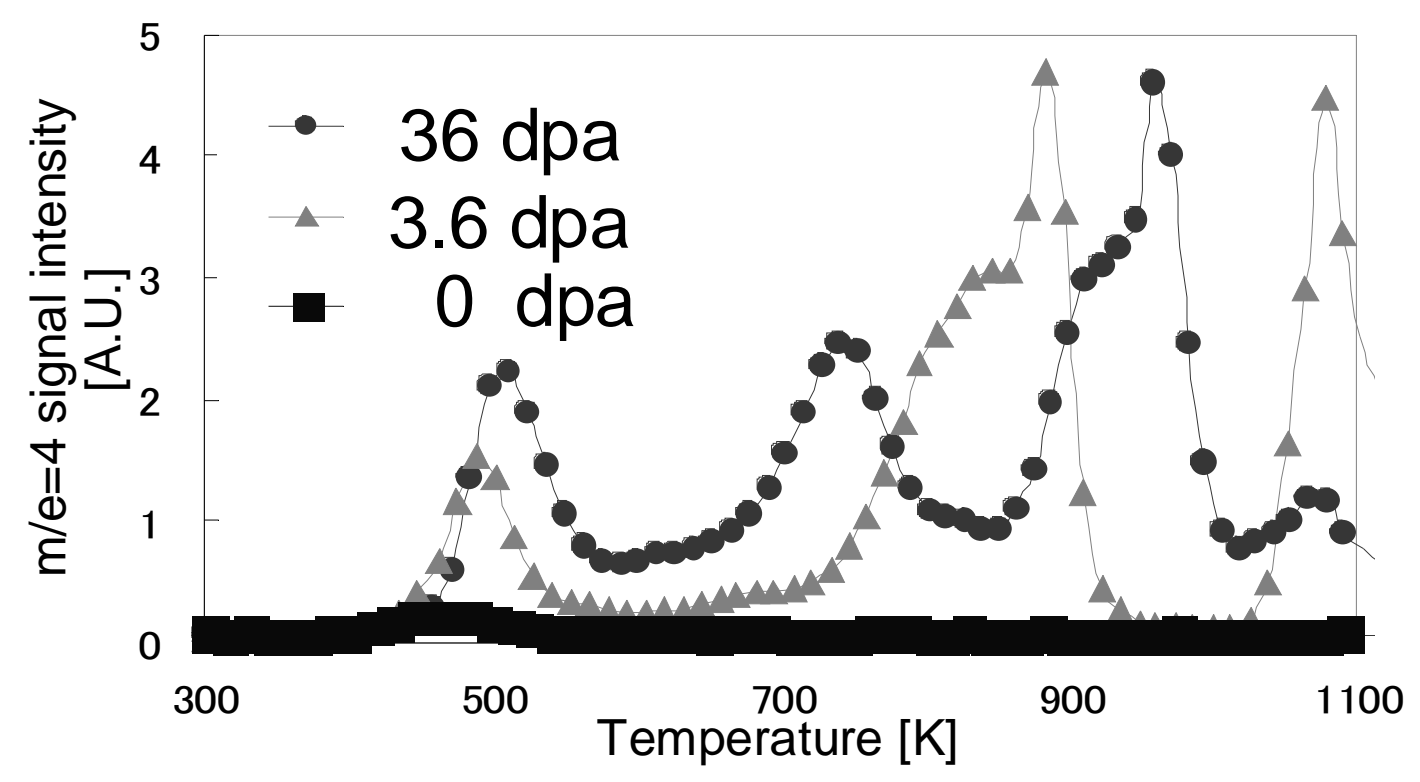

Figure 3 Time evolution of $\mathrm{m} / \mathrm{e}=4$ signal intensity during the TDS measurement for F82H samples with or without the helium pre-irradiation. 
Y. Yamauchi Figure 4 (1/3 of one column)

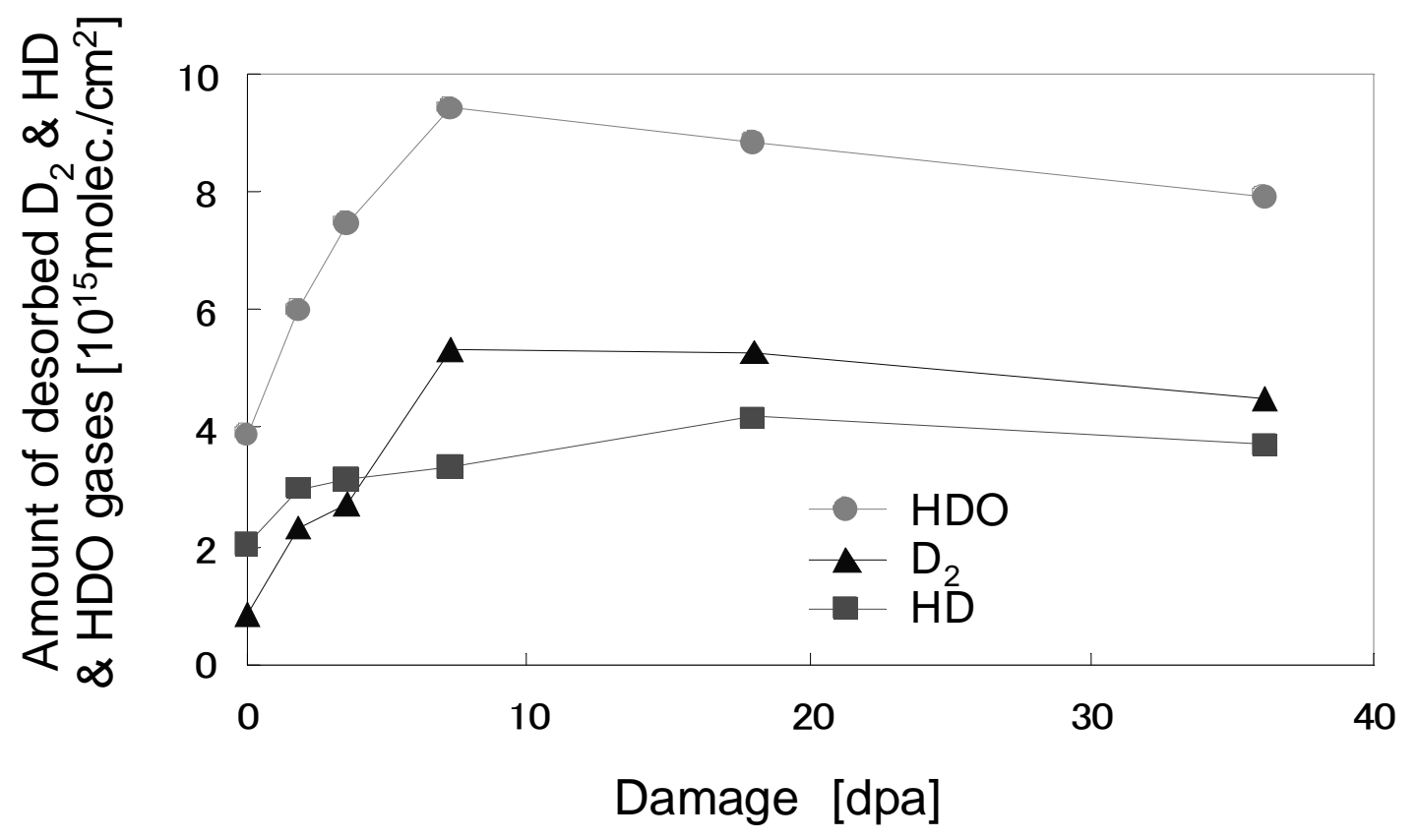

Figure 4 Amount of desorbed gases containing deuterium atoms from the deuteriumirradiated F82H as a function of the surface damage introduced by helium ion irradiation prior to the deuterium ion irradiation. 


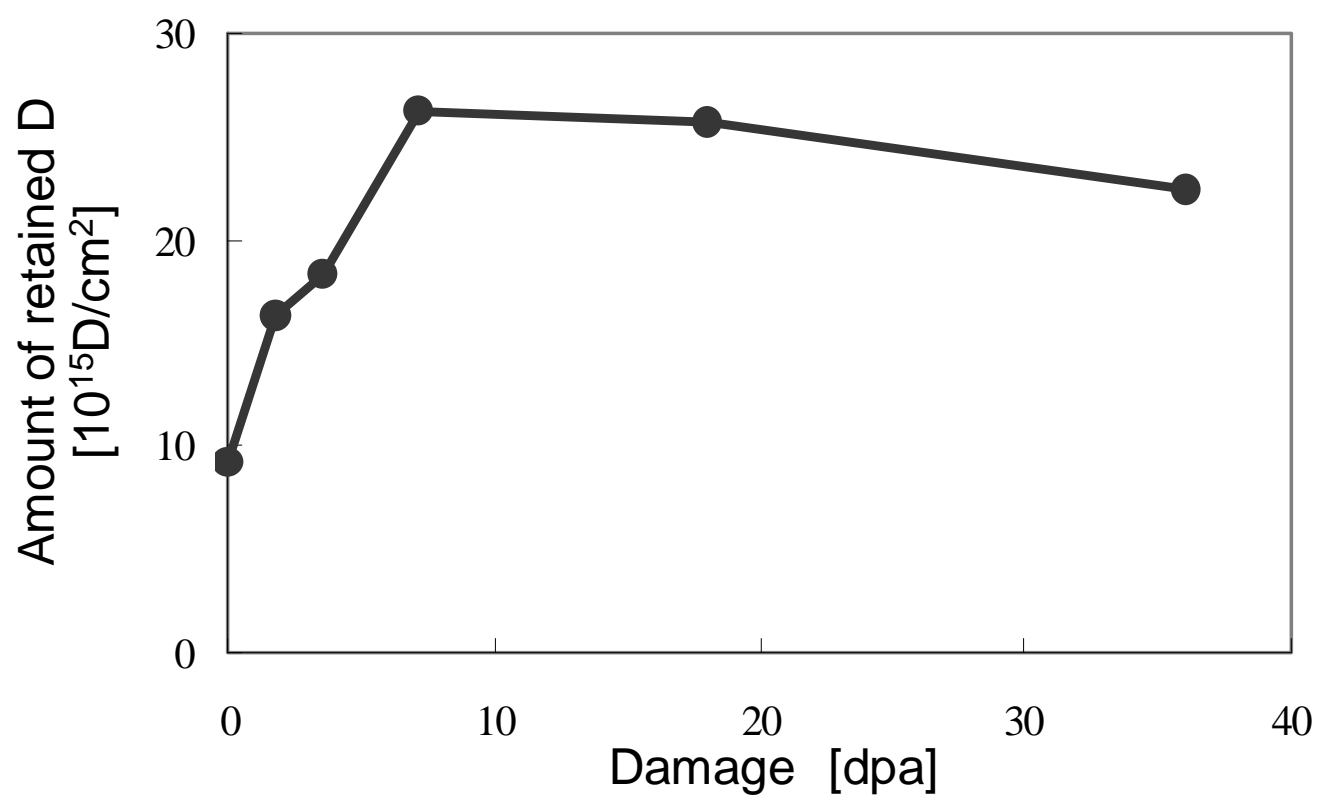

Figure 5 Amount of retained deuterium as a function of surface damage introduced by helium ion irradiation prior to the deuterium ion irradiation. 